\title{
LAS FORMAS DE TRATAMIENTO EN UN CORPUS DE ENTREVISTAS SEMIDIRIGIDAS DE ESPAÑOL DE GALICIA
}

\author{
María SAmpedro Mella* \\ Universidad de Salamanca \\ maria.sm@usal.es
}

Recibido: 06/11/2014

Aceptado: 20/04/2015

\begin{abstract}
Resumen
Este trabajo comprende un estudio de las formas de tratamiento en el corpus de entrevistas semidirigidas perteneciente a PRESEEA - Santiago de Compostela - ES y a ESLORA. Tras una introducción de la muestra objeto de estudio seleccionada para esta investigación y una síntesis bibliográfica sobre el estado de las formas de tratamiento en el español, se incluyen los resultados de la revisión de los usos de tú/usted, según la incidencia de diferentes factores sociales (inherentes a los propios hablantes) y contextuales. A partir de los resultados obtenidos, una parte de este trabajo se centra en el estudio cualitativo de un aspecto de interés hallado en el análisis: la variación de tú/usted que se produce ante un mismo interlocutor a lo largo de la misma entrevista, debido a diferentes causas.

PALABRAS CLAVE: formas de tratamiento, ESLORA, PRESEEA, análisis de corpus, entrevista semidirigida.
\end{abstract}

\begin{abstract}
This work is a study of address forms in the semi directive interview corpus belonging to PRESEEA Santiago de Compostela - ES and to ESLORA. After an introduction regarding the sample of study selected for this research and a bibliographical synthesis about the status of address forms in Spanish, the results of the tú/usted uses are included, according to the influence of different social (inherent to the speakers) and contextual factors. From these results, a part of this work focuses on the qualitative study of an interesting aspect that was found in the analysis: the variation of tú/usted that happens in the presence of the same interlocutor along the same interview, due to different causes.
\end{abstract}

KEY WORDS: address forms, ESLORA, PRE$S E E A$, corpus analysis, semi directive interview.

\footnotetext{
* Este trabajo forma parte de la investigación de mi tesis doctoral, para la que cuento con una beca de Formación de Profesorado Universitario (FPU, referencia AP2010-5977). Se inició en 2010 como parte de un Trabajo Académicamente Dirigido bajo la tutela de la profesora Dra. Vázquez Rozas (Universidade de Santiago de Compostela) y en 2012 se incrementó dando lugar a un Trabajo Fin de Doctorado, dirigido por la profesora Dra. Fernández Juncal (Universidad de Salamanca).
} 


\section{Introducción}

El presente artículo sobre el uso de las formas de tratamiento se basa en el análisis de un conjunto de entrevistas semidirigidas pertenecientes al corpus PRESEEA - Santiago de Compostela - ES ${ }^{1}$ y que también forman parte de ESLORA (Corpus para el estudio del español oral $)^{2}$, realizadas en la ciudad de Santiago de Compostela. Las grabaciones tienen una duración de aproximadamente cuarenta y cinco minutos y los informantes se seleccionaron a partir de las indicaciones de PRESEEA (2003) sobre la muestra poblacional: varones y mujeres residentes en la ciudad como mínimo durante los últimos 20 años y pertenecientes a tres grupos generacionales, en los que el primero comprende edades desde los 20 años hasta los 34, el segundo abarca desde los 35 hasta los 54 años y el tercero reúne hablantes a partir de los 55 años en adelante. El grado de instrucción también se divide en tres niveles: el primero incluye individuos que carecen de estudios o únicamente disponen de enseñanza primaria, el segundo está integrado por hablantes con estudios primarios y secundarios completos, y el tercero engloba a aquellos con estudios universitarios o de enseñanza superior (Moreno Fernández, 2005: 127 y ss.). A continuación se presenta una tabla que resume el perfil social de la muestra de PRESEEA:

\begin{tabular}{|l|c|c|c|c|c|c|}
\cline { 2 - 7 } \multicolumn{1}{c|}{} & \multicolumn{2}{c|}{ Generación 1 } & \multicolumn{2}{c|}{ Generación 2 } & \multicolumn{2}{c|}{ Generación 3 } \\
\cline { 2 - 7 } \multicolumn{1}{c|}{} & $\mathrm{H}$ & $\mathrm{M}$ & $\mathrm{H}$ & $\mathrm{M}$ & $\mathrm{H}$ & $\mathrm{M}$ \\
\hline Grado de instrucción 1 & 3 & 3 & 3 & 3 & 3 & 3 \\
\hline Grado de instrucción 2 & 3 & 3 & 3 & 3 & 3 & 3 \\
\hline Grado de instrucción 3 & 3 & 3 & 3 & 3 & 3 & 3 \\
\hline
\end{tabular}

Tabla 1: Distribución de la muestra-tipo de PRESEEA ${ }^{3}$

Para este trabajo, se han analizado las 18 entrevistas semidirigidas pertenecientes al grupo de estudios superiores o de grado de instrucción 3, que incluyen representantes varones y mujeres de los tres grupos de edades. El objetivo es revisar las formas de tratamiento utilizadas por ambos interlocutores -entrevistador y entrevistado- y la variación de uso que presentan en algunos casos. Para ello, se ha escogido este género discursivo, la entrevista semidirigida -también denominada “conversación semidirigida" (Vázquez Veiga, 1995) o "conversación grabada" (Silva-Corvalán, 2001)-, porque es un género híbrido entre la

1 El Proyecto para el Estudio Sociolingüístico del Español de España y América (PRESEEA), en el que colaboran diferentes universidades de España e Hispanoamérica, tiene como objetivo reunir un macrocorpus oral representativo del mundo hispánico en su variedad geográfica y social, que posibilite su aplicación con fines educativos y tecnológicos. Para ello se utiliza la técnica de la entrevista semidirigida, que se aplica a una muestra poblacional sociolingüísticamente representativa de un gran número de ciudades de ámbito hispánico. Para más información, vid. http://preseea.linguas.net, Moreno Fernández (1996, 2005) y Cestero Mancera (2013).

2 Al presente, estas entrevistas semidirigidas solo están disponibles a través de ESLORA (http://galvan.usc.es/ eslora), un corpus informatizado que se desarrolla actualmente en la Universidade de Santiago de Compostela como parte del Proyecto para el Estudio Sociolingüístico del Español de Galicia (PRESEGAL). Contiene, además de entrevistas, conversaciones espontáneas registradas en Galicia entre 2007 y 2014 . Para más información, vid. http://gramatica.usc.es/proxectos/eslora/ y Vázquez Rozas (en prensa).

3 Fuente: http:// preseea.linguas.net/Metodolog\%C3\%ADa.aspx. 
conversación espontánea y la entrevista prototípica cuyo objetivo es registrar muestras de habla naturales, propias del estilo espontáneo o vernáculo (cf. Labov, 1966) y que ofrece al investigaror información relativa a los hablantes. Además, al contrario que otros corpus de lengua oral (CREA, Davies, 2002), PRESEEA ofrece acceso al texto completo y, por tanto, los datos extraídos se estudian en su contexto total.

\section{Las formas de tratamiento}

Las formas de tratamiento son un reflejo de cómo se sitúan los interlocutores en el discurso: el uso de un sistema simétrico revela igualdad y proximidad entre hablantes, mientras que el empleo de un sistema asimétrico indica un desequilibrio de la relación social, que exige la presencia de estrategias de cortesía (Calsamiglia y Tusón, 2007: 149). En la actualidad son numerosos los estudios llevados a cabo sobre el uso de las formas de tratamiento ${ }^{4}$, si bien no existe unanimidad en lo relativo a los factores que determinan la elección pronominal, dentro del español o en términos generales en aquellos códigos con una marca ${ }^{5}$, ya que "aunque se trata de una forma de comportamiento universal, existen grandes diferencias entre las lenguas, no s[o]lo en cuanto a la manifestación formal de la misma, sino también en cuanto al comportamiento interactivo" (Havertake, 1994: 12).

Como señala Fernández (2003), la mayoría de los trabajos sobre las formas de tratamiento publicados después de los años 60 están basados en la propuesta teórica de Brown y Gilman (1968) (Calderón y Medina Morales, 2010; Medina López, 2010, etc.). Estos autores distinguen un primer eje horizontal de solidaridad, correspondiente a la distancia y proximidad entre interactuantes, basado en su grado de conocimiento mutuo, la relación afectiva o el tipo de situación en la que se encuentran (formal, ceremonial o informal) y un segundo eje vertical de poder que surge a partir de ciertas diferencias: fuerza física, riqueza, edad, sexo, papel institucionalizado en la iglesia, en el estado, la armada o la familia (Brown y Gilman, 1968: 255) ${ }^{6}$. Blas Arroyo (1995: 231) cuestiona este modelo, puesto que

ni el poder ni la solidaridad son factores estáticos que determinan mecánicamente un tratamiento categórico (...) puede ocurrir perfectamente que un locutor que ocupa un nivel jerárquicamente superior al de otro $-\mathrm{y}$ del que recibe la forma $\mathrm{V}-(\ldots)$ devuelva esa misma forma de tratamiento y no $\mathrm{T}$.

Otra teoría ampliamente adoptada en los estudios sobre cortesía es la de Brown y Levinson (1987) (Blas Arroyo, 1995; Pedroviejo Esteruelas, 2003; Zambrano-Paff, 2006). Estos autores consideran que la cortesía es un fenómeno universal necesario para evitar el conflicto. Para

4 Una amplia selección bibliográfica se encuentra en Fernández (2006).

5 En Frías Conde (2011: 6 y ss.) se establece una triple distinción entre aquellas lenguas "sin marca", es decir, con un único pronombre de segunda persona, como el inglés; de aquellas "con una marca", caso del español, el italiano, el francés, el checo, el ruso o el chino, o con "doble marca", como el rumano.

6 En Medina López (1990) puede encontrarse una aplicación de los conceptos poder y solidaridad de estos autores específicamente en las formas de tratamiento del español. En una perspectiva más amplia, Weinerman (1976: 57 y ss.) recoge una visión de esta teoría a través de la recopilación de distintos estudios sobre la dualidad de segunda persona en varias lenguas, como el ruso, el guaraní, el inglés, el español, el francés, etc. 
exponer su teoría, reintroducen el concepto goffniano de imagen o $\mathrm{face}^{7}$, al que asocian la necesidad de mantener la propia imagen y la de los demás, hecho que exige, por tanto, suavizar los actos amenazantes a través de distintos procedimientos corteses. Por otra parte, el nivel de cortesía que se debe emplear depende de otros factores, como el poder relativo -relative power- de un hablante sobre otro, la distancia social-social distance- existente entre ellos y el nivel de imposición - ranking of the imposition- del acto amenazante (Brown y Levinson, 1987: 15). De este modo, las formas de tratamiento están destinadas a minimizar esa posible carga amenazante contra el destinatario, y el uso de la forma tú se relacionaría con la denominada cortesía positiva y el de la forma usted con la negativa ${ }^{8}$. Esta teoría presenta algunos inconvenientes, como la propia noción de face, demasiado abstracta, o la independencia entre la imagen positiva y la negativa, por ejemplo, con la que no todos están de acuerdo.

Conjugando ambas teorías, se puede ver una necesidad en los hablantes por mantener un equilibrio en la relación social y querer evitar cualquier tipo de conflicto. Autores como Cots (1998) o Escavy Zamora (2008), en la misma línea de Goffman (1970), consideran que la creación y definición del propio sujeto (own self) se produce a partir de las reacciones de los demás, ya que el individuo en sí mismo no posee una realidad propia, sino que esta se manifiesta a través de su interacción social; en otras palabras, las personas alcanzan una definición de sí mismas a través de las respuestas de otros. En consecuencia, el interés de los participantes en obtener el mayor grado posible de coordinación en la interacción discursiva se debe a una necesidad, no solo de comunicar cierta información, sino también de construir un "yo" deseable que se ajuste a sus aspiraciones (Cots, 1998: 93). En términos de Escavy Zamora (2008:157-158):

En las relaciones interpersonales, uno trata de acomodarse a las circunstancias para evitar un desequilibrio arriesgado de la imagen. El habla es el instrumento posiblemente más importante con el que uno cuenta para darse a conocer a los demás, a través del cual se lleva a cabo el proceso de valoración del interlocutor.

La actuación del individuo no responde únicamente a la proyección interesada de sus propios deseos de imagen, sino que debe, a su vez, satisfacer y ajustarse a las expectativas del otro (Hernández Flores, 2005: 100). Para ello se emplean una serie de estrategias lingüísticas, que responden en mayor o menor medida al tipo de relación que se establece entre ellos, de poder o de solidaridad, hecho que se traduce en el uso de un sistema de tratamientos simétrico o no simétrico. El problema, entonces, es determinar cuáles son los factores que disponen el tipo de relación, que no se ciñen a cuestiones normativas, sino al uso real (y variable) de los hablantes nativos "para expresar su identidad personal y grupal, además de para delimitar espacios situacionales e ideológicos” (Mas Álvarez, 2014: 10). A partir de la demarcación del tipo de relación entre hablantes parece, entonces, relativamente fácil intuir la forma de tratamiento que utilizarán en su discurso.

7 Para Goffman (1970), la imagen o face es el valor social positivo que un individuo reclama para sí a través de la valoración de otros en un contacto particular. Por consiguiente, las personas han de llevar a cabo trabajos de imagen (face work) en sus relaciones sociales, a fin de conseguir una imagen pública que se ajuste a sus expectativas $\mathrm{y}$ a las de su interlocutor, en su entorno social.

8 Carrasco Santana (1999) en un completo examen sobre el modelo de Brown y Levinson (1987) encuentra que los términos de cortesía positiva y negativa entrañan algunos problemas terminológicos, por lo que prefiere referirse a estas nociones como cortesía valorizante y mitigadora. 
A continuación se presentan algunas síntesis de los criterios que conforman una relación jerárquica, que han apuntado algunos autores en términos generales o específicamente sobre el uso de las formas de tratamiento: Solé (1978: 5), a propósito de la enseñanza de estas formas a extranjeros, resume en cinco los indicios que hacen presuponer el uso de tú o usted:

(1) the interpersonal relationship of the speakers; (2) the norms governing personal relationships within a given setting; (3) the personal characteristics of the speakers -country of origin, rural/urban procedence, level of education, sex and age; (4) the speech context in which the exchange occurs; and (5) the neutrality or affectivity of the speech event itself.

Escandell (1995: 31; 2006: 136) apunta la importancia de la identidad social del destinatario y factores sociales, como la edad, el sexo, el grado de conocimiento previo, la posición social, la autoridad, la jerarquía, etc. De manera análoga, Hernández Flores (2005: 100) afirma que el hablante confirma la imagen de su interlocutor en relación con el rol que representa ante esa situación, al tiempo que confirma la suya propia, de acuerdo también con su rol. Por otra parte, Bravo (2005: 25) prioriza el

contexto sociocultural que comparten los hablantes [...], redes sociales, la clase socioeconómica, factores culturales como el conocimiento compartido, las creencias y valores, factores demográficos y sociales como la edad, el sexo, la educación, la clase social y el lugar de residencia, la identidad étnica o nacional.

Rodríguez Mendoza (2003: 64 y ss.) destaca en su tesis doctoral que la forma tú suele emplearse en situaciones caracterizadas por la "intimidad psicológica o complacencia social", es decir, en situaciones de familiaridad o de formalidad baja, mientras que usted es la alternativa formal, también utilizada para marcar distancia social, respeto, deferencia, etc., y para tratar a personas desconocidas.

Por su parte, la $N G L E$ (2009: 16.15a.), en una línea similar, menciona los siguientes aspectos:

Intervienen en la elección de las formas pronominales de tratamiento la confianza que exista entre los interlocutores, la cercanía, la solidaridad, la intimidad, el respeto, el nivel del que recibe el trato en relación con el de quien lo otorga, la situación comunicativa y su grado de formalidad, además de otros factores similares.

Calderón Campos (2010: 233) prescinde de los conceptos de "respeto" y "deferencia", y alude también a la "solidaridad, confianza e intimidad" de ciertas situaciones:

El trato de tú o vos implica proximidad con el interlocutor en alguno de estos tres grados señalados. Por tanto, se pueden utilizar tú o vos si el hablante considera que le une con el interlocutor una relación de solidaridad, confianza o intimidad. Por el contrario, se elige usted para indicar distancia (jerárquica, social, etaria, etc.). Además, independientemente de este rasgo de proximidad apuntado, siempre es posible dirigirse al interlocutor de tú o vos cuando [e]ste es joven, especialmente cuando se trata de niños o adolescentes. Este es el único caso en que el uso de tú o vos no sirve para expresar cercanía, si no que viene exigido por la asimetría etaria. En todos los demás casos, la elección de usted o tú/vos viene determinada por el deseo, la conveniencia o la obligación del hablante de marcar más o menos la distancia. 
Como se puede observar, en conjunto tienden a distinguirse aquellas variables inherentes a la naturaleza social de los interlocutores de las que tienen que ver con la relación que se establece entre ellos, sin dar cuenta del orden en el que participan en la creación de una situación jerárquica o simétrica que condicionará la elección de una u otra forma pronominal. En relación con esto, algunos autores como Alba de Diego y Sánchez Lobato (1980), Blas Arroyo (1994a, 1995), Morín Rodríguez (1997), Aijón Oliva (2009), etc. constatan a partir de diferentes trabajos de campo (fundamentalmente encuestas y análisis de corpus) que suele ser la edad el factor más influyente, que da lugar a la elección de un sistema de tratamiento solidario o no solidario (cf. Alba de Diego y Sánchez Lobato) ${ }^{9}$.

Por último, hay que tener en cuenta que este cambio en el español es más acusado que en otras lenguas del entorno con una marca e incluso en algunas variedades del español se produce con mayor acentuación que en otras (Molina Martos, 2002: 98). Ridruejo (1989) considera que esto se debe a que los hablantes sienten una preferencia hacia el tuteo, porque indica igualdad, frente al ustedeo, muestra de distanciamiento y de desigualdad social, hecho que también constatan Blas Arroyo (1994a: 21 y ss.) o Garrido Medina (1992: 1063), quien defiende lo siguiente:

A medida que la movilidad social y la ideología igualitaria se extienden, el sistema de tratamiento se inclina hacia la dimensión de la igualdad (es decir, la expresión de la distancia o de la familiaridad), en detrimento de la dimensión de la desigualdad, es decir la expresión de las relaciones de inferioridad o superioridad sociales.

Molina Martos (2002: 100) señala directamente a los jóvenes universitarios como promotores de este cambio, debido a la influencia igualitaria de la universidad, afirmación que años atrás realizaron Borrego Nieto, Gómez Asencio y Pérez Bowie (1978) derivada de una investigación que se llevó a cabo con encuestas a alumnado universitario de distintas edades ${ }^{10}$.

\section{Las formas de tratamiento en el corpus de entrevistas semidirigidas}

El contexto que nos ocupa, la entrevista semidirigida, se regula por una serie de normas discursivas y también sociales: los roles de los participantes están determinados con anterioridad al encuentro, la toma de turno está predeterminada y el registro empleado acostumbra a ser semiformal de acuerdo con el contexto, por lo que debe "rebajarse". Sin embargo, la incorporación de nuevos temas o la formulación de las preguntas se aproximan más en estos casos al género conversacional que a la entrevista prototípica (Albelda Marco, 2005: 112). En consecuencia, las muestras evidencian un registro más formal por parte del entrevistado y un posible exceso de control sobre su habla (Recalde y Vázquez Rozas, 2009), lo que de-

9 A este respecto, Aijón Oliva (2009: 23), en un análisis de anuncios publicitarios, destaca la importancia de la imagen que quiere proyectar el emisor, con el fin de persuadir más sobre el posible comprador.

10 Otros trabajos más recientes sobre estudiantes universitarios y, también basados en la técnica de encuesta son: Aguado Candanedo (1981) en Bilbao, Blas Arroyo (1994b) en la Comunidad Valenciana, con informantes de distintas edades; Molina Martos (2002) en Madrid, Rodríguez Mendoza (2003) en San Sebastián de la Gomera, Pedroviejo Esteruelas (2006) en Valladolid, Montero Curiel (2011) en Extremadura y Sanromán (2013) en Santiago de Compostela y Coruxo (con el fin de comparar posibles diferencias de uso entre ámbito urbano y rural). 
bería también repercutir en un mayor empleo del pronombre usted, más formal. No obstante, Morín Rodríguez (1997), en un estudio basado en el uso de las formas de tratamiento en un contexto laboral, afirma lo siguiente:

El ámbito laboral, al igual que cualquier otro marco situacional comunicativo, determina "a priori" el uso de un específico registro lingüístico (familiar, formal...), aunque es en definitiva el contexto situacional concreto quien fija la elección lingüística. Actores como la 'edad' o el 'nivel sociocultural' del hablante, o bien el 'sexo' o el 'estatus' del destinario son, sin duda, marcadores relevantes (Morín Rodríguez, 1997: 287).

En las entrevistas, los interlocutores, salvo en uno de los casos estudiados, no se conocían hasta el momento del encuentro (vid. tabla 2). En lo relativo al entrevistador, en PRESEEA no se tiene en cuenta su perfil, si bien algunos autores (Labov, Silva-Corvalán) consideran de vital importancia sus características sociales en la interacción: "mientras más similares sean las características sociales del investigador y el hablante, mayores serán las posibilidades de obtener habla espontánea y no formal" (Silva-Corvalán, 2001: 56). En ESLORA sí aparece información relativa al perfil social del entrevistador y se especifica, además, si conocía previamente al informante, lo que permite estudiar con mayor profundidad el tipo de relación que se establece entre ellos -jerárquica o igualitaria-, a tenor de sus características sociales.

En casi el total de la muestra seleccionada para este trabajo los rasgos del entrevistador son los siguientes: mujer, menor de 30 años y con estudios universitarios; las excepciones son tres entrevistas realizadas por varones del mismo perfil social ${ }^{11} \mathrm{y}$ otras dos de mujeres del segundo grupo de edad, también de estudios universitarios ${ }^{12}$. Por tanto, interesa señalar que los interlocutores pertenecen, a priori, a la misma categoría social (estudios universitarios), por lo que los rasgos más destacables en la constitución de su relación son el contexto de la entrevista y las posibles diferencias de edad y sexo.

Del conjunto de las dieciocho entrevistas, en diez de ellas se produce un sistema simétrico de tuteo recíproco entre los interlocutores $(55,5 \%)$ y tan solo en una de ellas (SCOM M33_009) hay un sistema asimétrico en el que la informante trata de tú a la entrevistadora y esta de usted a la entrevistada, lo que representa un 5,5\% del total. En lo relativo a las restantes entrevistas (39\%), interesa destacar que todas presentan alguna variación en la forma de tratamiento seleccionada, que analizaremos en el apartado 5. Así, en cinco de ellas $(27,7 \%)$ el informante tutea al entrevistador, mientras que este utiliza ambas formas de tratamiento para dirigirse a él; en una $(5,5 \%)$ es el informante quien emplea las dos formas de apelativas con su entrevistador, quien, a su vez, lo trata de usted y, finalmente, también en una entrevista $(5,5 \%)$ ambos participantes utilizan los dos pronombres con su respectivo interlocutor.

11 SCOM_H23_003,SCOM_H23_006 y SCOM_M33_011.SCOM es el acrónimo que utiliza PRESEEA (2008) para identificar a la ciudad de Santiago de Compostela La descripción de las claves es la siguiente: "SCOM" es el acrónimo que utiliza PRESEEA (2008) para identificar a la ciudad de Santiago de Compostela , "M" o "H" representa el sexo del informante, el primer número que aparece señala el grupo de edad al que pertenece el entrevistado $(1,2$ o 3$)$ y el segundo se refiere al nivel de estudios (en este caso, el 3 indica que se trata de estudios superiores). Finalmente, los números restantes identifican específicamente a cada entrevista.

12 SCOM_H33_015 y SCOM_M13_010. 


\begin{tabular}{|c|c|c|c|c|c|c|c|c|}
\hline $\begin{array}{l}\text { Código } \\
\text { Entrevista }\end{array}$ & $\begin{array}{c}\operatorname{Sexo} \\
I^{13}\end{array}$ & $\begin{array}{c}\text { Edad } \\
\text { I }\end{array}$ & $\begin{array}{l}\text { Titulación/ } \\
\text { Profesión } \\
\text { I }\end{array}$ & $\begin{array}{c}\text { Sexo } \\
\mathbf{E}\end{array}$ & $\begin{array}{c}\text { Edad } \\
\mathbf{E}\end{array}$ & $\begin{array}{l}\text { Titulación/ } \\
\text { Profesión } \\
\text { E }\end{array}$ & $\begin{array}{l}\text { Con. } \\
\text { previo } \\
\text { I-E }\end{array}$ & $\begin{array}{c}\text { Tratamiento } \\
\text { utilizado }\end{array}$ \\
\hline SCOM_H13_012 & Varón & 21 & $\begin{array}{l}\text { Estudiante de } \\
\text { Periodismo }\end{array}$ & Mujer & 29 & Prof ${ }^{\mathrm{a}}$ instituto & No & $\begin{array}{l}\text { Tuteo } \\
\text { recíproco }\end{array}$ \\
\hline SCOM_H13_013 & Varón & 28 & Informático & Mujer & 24 & $\begin{array}{l}\text { Becaria de } \\
\text { investigación }\end{array}$ & No & $\begin{array}{l}\text { Tuteo } \\
\text { recíproco }\end{array}$ \\
\hline SCOM_H13_014 & Varón & 28 & $\begin{array}{c}\text { Productor y } \\
\text { realizador de vídeo }\end{array}$ & Mujer & 22 & $\begin{array}{c}\text { Estudiante } \\
\text { universitaria }\end{array}$ & No & $\begin{array}{c}\text { Tuteo } \\
\text { recíproco }\end{array}$ \\
\hline $\begin{array}{l}\text { SCOM_- } \\
\text { M13_016 }\end{array}$ & Mujer & 20 & $\begin{array}{c}\text { Estudiante de } \\
\text { Animación turística }\end{array}$ & Mujer & 20 & $\begin{array}{c}\text { Estudiante } \\
\text { universitaria }\end{array}$ & No & $\begin{array}{c}\text { Tuteo } \\
\text { Recíproco }\end{array}$ \\
\hline $\begin{array}{l}\text { SCOM_- } \\
\text { M13_010 }\end{array}$ & Mujer & 26 & $\begin{array}{l}\text { Lcda. en Psicología. } \\
\text { Becaria de aula de } \\
\text { informática }\end{array}$ & Mujer & 40 & $\begin{array}{c}\text { Prof }^{\mathrm{a}} \\
\text { universitaria }\end{array}$ & No & $\begin{array}{l}\text { Tuteo } \\
\text { Recíproco }\end{array}$ \\
\hline $\begin{array}{l}\text { SCOM_- } \\
\text { M13_008 }\end{array}$ & Mujer & 29 & Odontóloga & Mujer & 24 & $\begin{array}{l}\text { Becaria de } \\
\text { investigación }\end{array}$ & No & $\begin{array}{c}\text { Tuteo } \\
\text { Recíproco }\end{array}$ \\
\hline SCOM_H23_006 & Varón & 38 & Abogado & Varón & 25 & $\begin{array}{c}\text { Becario de } \\
\text { investigación }\end{array}$ & No & $\begin{array}{c}\text { Tuteo } \\
\text { Recíproco }\end{array}$ \\
\hline $\begin{array}{l}\text { SCOM_- } \\
\text { M23_018 }\end{array}$ & Mujer & 39 & $\begin{array}{l}\text { Profesora de } \\
\text { instituto }\end{array}$ & Mujer & 20 & $\begin{array}{c}\text { Estudiante } \\
\text { universitaria }\end{array}$ & No & $\begin{array}{c}\text { Tuteo } \\
\text { Recíproco }\end{array}$ \\
\hline $\begin{array}{l}\text { SCOM_- } \\
\text { M23_001 }\end{array}$ & Mujer & 50 & $\begin{array}{c}\text { Lcda. en } \\
\text { Magisterio. Admva. }\end{array}$ & Mujer & 24 & $\begin{array}{c}\text { Becaria de } \\
\text { investigación }\end{array}$ & No & $\begin{array}{c}\text { Tuteo } \\
\text { Recíproco }\end{array}$ \\
\hline SCOM_H33_015 & Varón & 74 & Sacerdote & Mujer & 47 & $\begin{array}{c}\text { Prof }^{\mathrm{a}} \\
\text { universitaria }\end{array}$ & Sí & $\begin{array}{c}\text { Tuteo } \\
\text { Recíproco }\end{array}$ \\
\hline $\begin{array}{l}\text { SCOM_- } \\
\text { M33_009 }\end{array}$ & Mujer & 74 & Maestra jubilada & Mujer & 19 & $\begin{array}{c}\text { Estudiante } \\
\text { universitaria }\end{array}$ & No & $\begin{aligned} \mathrm{I} & \rightarrow \mathrm{E} \text { tú } \\
\mathrm{E} & \rightarrow \mathrm{I} \mathrm{Vd} .\end{aligned}$ \\
\hline SCOM_H23_003 & Varón & 38 & $\begin{array}{c}\text { Lcdo. en } \\
\text { Filología Clásica. } \\
\text { Comerciante }\end{array}$ & Varón & 20 & $\begin{array}{c}\text { Estudiante } \\
\text { universitario }\end{array}$ & No & $\begin{array}{c}\mathrm{I} \rightarrow \mathrm{E} \text { tú } \\
\mathrm{E} \rightarrow \mathrm{I} \text { tú/Vd. }\end{array}$ \\
\hline SCOM_H23_017 & Varón & 47 & $\begin{array}{l}\text { Lcdo. en Derecho. } \\
\text { Funcionario }\end{array}$ & Mujer & 22 & $\begin{array}{c}\text { Estudiante } \\
\text { universitaria }\end{array}$ & No & $\begin{array}{c}\mathrm{I} \rightarrow \mathrm{E} \text { tú } \\
\mathrm{E} \rightarrow \mathrm{I} \text { tú/Vd. }\end{array}$ \\
\hline $\begin{array}{l}\text { SCOM_- } \\
\text { M23_004 }\end{array}$ & Mujer & 46 & Enfermera & Mujer & 23 & Prof ${ }^{a}$ instituto & No & $\begin{array}{c}\mathrm{I} \rightarrow \mathrm{E} \text { tú } \\
\mathrm{E} \rightarrow \mathrm{I} \text { tú/Vd. }\end{array}$ \\
\hline SCOM_H33_007 & Varón & 61 & Arquitecto & Mujer & 22 & $\begin{array}{c}\text { Estudiante } \\
\text { universitaria }\end{array}$ & No & $\begin{array}{c}\mathrm{I} \rightarrow \mathrm{E} \text { tú } \\
\mathrm{E} \rightarrow \mathrm{I} \text { tú/Vd. }\end{array}$ \\
\hline $\begin{array}{l}\mathrm{SCOM} \\
\mathrm{M} 23 \_005\end{array}$ & Mujer & 67 & $\begin{array}{c}\text { Farmacéutica } \\
\text { jubilada }\end{array}$ & Mujer & 22 & $\begin{array}{c}\text { Estudiante } \\
\text { universitaria }\end{array}$ & No & $\begin{array}{c}\mathrm{I} \rightarrow \mathrm{E} \text { tú } \\
\mathrm{E} \rightarrow \mathrm{I} \text { tú/Vd. }\end{array}$ \\
\hline SCOM_H33_002 & Varón & 61 & $\begin{array}{c}\text { Comerciante } \\
\text { jubilado }\end{array}$ & Mujer & 19 & $\begin{array}{c}\text { Estudiante } \\
\text { universitaria }\end{array}$ & No & $\begin{array}{c}\mathrm{I} \rightarrow \mathrm{E} \text { tú/Vd. } \\
\mathrm{E} \rightarrow \mathrm{I} \mathrm{Vd} .\end{array}$ \\
\hline $\begin{array}{l}\text { SCOM } \\
\text { M33_011 }\end{array}$ & Mujer & 75 & $\begin{array}{c}\text { Profesora } \\
\text { universitaria } \\
\text { jubilada }\end{array}$ & Varón & 25 & $\begin{array}{l}\text { Becario de } \\
\text { investigación }\end{array}$ & No & $\begin{array}{l}\mathrm{I} \rightarrow \mathrm{E} \text { tú/Vd. } \\
\mathrm{E} \rightarrow \mathrm{I} \text { tú/Vd. }\end{array}$ \\
\hline
\end{tabular}

Tabla (2) Síntesis de la muestra: perfil social de los interlocutores, relación entre ellos y tratamiento utilizado.

13 Cabe señalar que se han mantenido las abreviaturas de los participantes empleadas en este corpus, pero no en el conjunto de PRESEEA; así, 'E' equivale al entrevistador e 'I' al informante o entrevistado. 

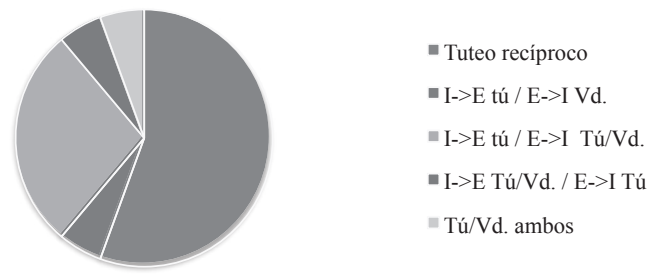

Gráfica 1: Número de entrevistas según el diferente tratamiento representado.

De acuerdo con los datos, el tuteo es la forma predominante, con un porcentaje superior a la mitad del conjunto; se observa, además, que se utiliza fundamentalmente en aquellos casos en los que los interlocutores son ambos jóvenes, menores de 40 años ${ }^{14}$-en su mayoría, de 30 años-. Tan solo hay dos casos de entrevistados de mayor edad a esta: la entrevista SCOM_M23_001, en la que la informante tiene 50 años y la entrevistadora 24, y la entrevista SCOM_H33_015, en la cual el informante tiene 74 años y la entrevistadora 47, si bien se conocían con anterioridad al encuentro. Estos datos se corresponden parcialmente con los de la bibliografía especializada (Alba de Diego y Sánchez Lobato, 1980: 98; Blas Arroyo, 1994a: 8; Matte Bon, 1995; Aijón Oliva, 2009), que indican que la edad y la pertenencia a una generación común dan lugar a una relación de solidaridad, traducida en el empleo común del mismo pronombre de segunda persona. Con todo, este factor no es exclusivo, ya que la afectuosidad o la cercanía de los entrevistados puede influir también en la forma adoptada por los entrevistadores. Por su parte, el sexo no parece ser un factor incidente en la elección tú/usted, puesto que en la totalidad de las situaciones de tuteo, son mujeres las entrevistadoras que en un $50 \%$ de estos casos entrevistan a varones y en el otro $50 \%$ a mujeres.

Tan solo hay un ejemplo de sistema asimétrico sin variación pronominal: la entrevistadora, mujer de 19 años, ustedea a la informante, mujer de 74 años y esta, en cambio, la trata de $t u ́$; esta diferencia de edad parece ser la razón del uso de un sistema no solidario (cf. Alba de Diego y Sánchez Lobato). Las restantes entrevistas también presentan este mismo sistema de tratamiento, aunque en todas ellas se registra algún tipo de alternancia en el uso de las formas de tratamiento empleadas, que se examinará en el apartado 5.

\section{Alusiones a las formas de tratamiento}

Para abordar el estudio de las formas de tratamiento, PRESEEA dispone de un cuestionario específico ${ }^{15}$ utilizado, por ejemplo, en la investigación de Molina Martos (2002), y cuyas ventajas metodológicas pueden consultarse en Paredes (2010). Sin embargo, esta herramienta no ha sido empleada en PRESEGAL, al considerar que no refleja los usos lingüísticos reales de los hablantes. La razón se debe a que se pregunta directamente, por ejemplo, la forma de tratamiento que se utiliza con interlocutores de distintas profesiones, sin tener en cuenta otros factores.

14 En Montero Curiel (2011: 113) se señala que el momento para ser tratado de usted comienza a los 40 años, edad con ciertas connotaciones sociales (veinteañero, treintañero vs. cuarentón) y marcada por el cambio a la madurez. En nuestro caso, representa el doble que tienen la mayoría de los entrevistadores.

15 Vid. http:// preseea.linguas.net/Portals/0/Metodologia/Cuestionario\%20FT.pdf 
En los módulos temáticos propuestos en PRESEEA (2003) para su aplicación en las entrevistas semidirigidas, aparece también la cuestión de los tratamientos en la sección dedicada a la presentación de los interlocutores, con la que se inicia el intercambio comunicativo:

¿Cómo quiere que le trate de tú o de usted? La verdad es que es un problema esto del tratamiento, nunca sabes c[ó]mo tratar a las personas ¿verdad? Por ejemplo, ¿tú cómo tratas a tus amigos de tú o de usted? ¿Y si son personas mayores? ¿Si se trata de alguien joven que no conoces? [...] ¿Si una persona más joven te/le trata de tú qué te/le parece? (Preguntar por si tratan de evitar el trato asimétrico o en qué situaciones les parece mejor). Es un problema, yo a veces no sé qué hacer. Bueno, a mí tráteme de tú ¿le/te parece?

En PRESEGAL, la utilización de estos módulos temáticos se ha limitado por los inconvenientes que conllevan las entrevistas estructuradas: excesivo control del entrevistador, rigidez del evento comunicativo, respuestas forzadas, etc. Así, con el fin de rebajar el nivel de formalidad y de obtener y registrar el habla espontánea, se ha procurado acomodar la entrevista a la personalidad de cada informante, a través de la introducción de temas que son de su agrado y que no necesariamente aparecen entre los recomendados por PRESEEA (2003) (vid. Fernández Sanmartín et alii, 2008; Vázquez Rozas, en prensa).

En el corpus analizado, las alusiones explícitas a las formas de trato son muy escasas (cuatro en total) y solo aparecen para establecer el tratamiento entre los participantes -aunque, como se verá en el siguiente apartado, no siempre se mantiene en toda la entrevista-. Las referencias al tratamiento tienen en común que se trata de peticiones o invitaciones de uno de los miembros para poder tutear al interlocutor o ser tuteado (no hay ningún caso en el que suceda hacia el usted). Por otro lado, la aparición explícita de estas formas se produce al comienzo del encuentro, cuando los interlocutores se reúnen por primera vez en persona, salvo en un caso (ejemplo 4) en el que ocurre en el minuto diecinueve. En todos estos ejemplos, además, los entrevistados tutean a los entrevistadores, por lo que el cambio al tú supone establecer un sistema solidario entre ambos interlocutores.

A diferencia de la propuesta incluida en los módulos temáticos de PRESEEA (2003), en los ejemplos de esta muestra la mención de las formas apelativas de segunda persona en la entrevista no se ha reutilizado para recabar datos sobre las creencias de uso de los tratamientos por parte de los informantes. Como se puede observar en los ejemplos (1) a (4), tras la referencia a dichas formas, se da comienzo a la entrevista (ejemplo 2) o se retoma el tema que se estaba tratando previamente: en (1) la explicación sobre el proyecto, en (3) el malentendido sobre el lugar de encuentro acordado por las interlocutoras y en (4) si es correcta la manera como está actuando la entrevistada en el intercambio comunicativo:

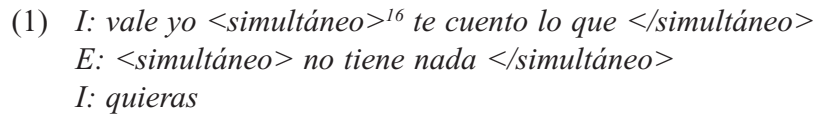

16 Se han mantenido las etiquetas en los ejemplos, tal y como aparecen en el corpus, puesto que aportan una mayor cantidad de información sobre el intercambio comunicativo. Las etiquetas representan elementos vocales y no vocales, como pausas, risas, estornudos, ruidos externos, etc. Turnos y solapamientos, fenómenos ininteligibles o de transcripción dudosa (cf. Llisterri, 1999). A esto hay que añadir algunos elementos léxicos, como alargamientos, citas, palabras cortadas, cambios de código, etc. En PRESEEA (2008) puede consultarse el listado de etiquetas mínimas obligatorias. 
E: después eeh ¿puedo tutearte?

I: sí / claro que sí <risas = "E"/> / yo también te he tuteado a ti / porque yo no estoy acostumbrada $<$ alargamiento/ $>$ /

E: no $<$ alargamiento/ $>$ / yo es que claro por $<$ simultáneo $>$ teléfono $<$ alargamiento/ $></$ simultáneo $>$

I: $<$ simultáneo $>$ ya $</$ simultáneo $>$ ya ya

E: no te conocía y tal / eemm / no mira / esto / aún están en clase <silencio/> pues eeh están $<$ alargamiento/> haciendo un estudio sobre <alargamiento/> la gente de Santiago / sus costumbres / modos de vida ... [SCOM_M23_018]

(2) E: ya encendí todas / todos los aparatos / bueno / eeh / usted se llama Marcos / yo me llamo Begoña

I: Marcos Budiño López /

E: vale / lo trataré de Marcos /

I: ¿eh?

E: ¿de usted o de tú?

I: de tú

E: vale

I: mis hijas me tratan de tú y tú no vas a ser menos/

E: no / porque soy igual <entre_risas> que su hija / más o menos </entre_risas > de la misma edad /

I: pues venga /

E: bueno / pues esto es un estudio <alargamiento/> sociológico que se está haciendo en la universidad de Santiago / y vamos a intentar estudiar los hábitos de vida que tienen las personas a las que entrevistamos / ¿me puede contar un poco a qué se dedica <alargamiento/> / en qué trabaja / en qué consiste su trabajo? / [SCOM_ H33_007]

(3) E: aunque no me acordé de pedirle el móvil

I: no no me trates de usted <risas = "E"/> pero bueno / tenías el de casa ¿o no?

E: sí el de casa <simultáneo > el fijo sí </simultáneo> [SCOM_M23_004]

(4) [...] yo no sé qué más quieres que te cuente / no sé si voy bien así contándote <simultáneo $>$ estas cosas o te estoy contando ¿qué? / bueno $</$ simultáneo $>$

E: <simultáneo > sí sí// o sea y / o sea </simultáneo> y usted se / <simultáneo>como / bueno como tú $</$ simultáneo $>$

I: $<$ simultáneo $>$ o o tú $<$ ininteligible $/>/$ bueno $</$ simultáneo $>$

E: $<$ simultáneo $>$ ¿de tú prefieres? $</$ simultáneo $>$

I: $<$ simultáneo $>$ de $<$ ininteligible $>$ sí $/</$ simultáneo $>$

E: $<$ simultáneo $>$ como prefieras $</$ simultáneo $>$

I: $<$ simultáneo $>$ sí prefiero de tú $/</$ simultáneo $>$

$E:<$ simultáneo $>$ bueno y cuando estabas $<$ risas $=" E " />/$ vale $</$ simultáneo $>$

I: $<$ simultáneo $>$ yo prefiero de $<$ ininteligible $><$ risas $=$ "I" $/></$ simultáneo $>$

E: $y$ cuando / eh

I: $<$ tiempo $=" 18.05 " />$ pregunta algo si quieres yo porque yo no estoy hablando pero no sé si estoy hablando bien <simultáneo $>$ o hablando mal </simultáneo $>$ [SCOM M33_011] 
En el ejemplo (1) la entrevistadora ha tratado de usted a la informante al concertar la cita telefónicamente y en la primera toma de contacto mantuvo el mismo tratamiento, pero tras comprobar que era mucho más joven de lo que pensaba decidió pedirle permiso para cambiar la forma de tratamiento. En (2) la entrevistadora pregunta al informante cómo prefiere ser tratado e ignora su respuesta tratándolo de usted; al preguntarle posteriormente el porqué de ese cambio afirmó no ser consciente de lo sucedido, y simplemente observó que era "más apropiada" la forma usted en el contexto en que se encontraba, lo que parece ser un indicio de la "naturalidad" en el uso de las formas de tratamiento también por parte de los entrevistadores; solo en una ocasión introduce una desinencia de segunda persona de singular, como veremos en el apartado 5.1.

En (3) es la entrevistada quien invita a la entrevistadora a tratarla de tú, por razones que se analizarán en el siguiente apartado $\mathrm{y}$, finalmente, en (4) se produce un pequeño malentendido fruto del continuo solapamiento entre ambos interlocutores en esta parte de la entrevista: la informante tutea al entrevistador, mientras que este la trata de usted, hasta que en este momento introduce el pronombre tú (hecho que repetirá en varias ocasiones, como se verá). La entrevistada pronuncia la siguiente secuencia solapada por varios turnos del entrevistador: no sé si voy bien así contándote estas cosas o te estoy contando ¿qué? / bueno o o tú <ininteligible/> / bueno. El entrevistador al oír la forma tú dirigida a él, parece que la interpreta como una invitación de la informante a tutearla, por lo que le pregunta directamente si quiere que la trate de tú, a lo que ella accede.

La mención directa de las formas de tratamiento es infrecuente, ya que podría constituir una amenaza a la imagen del interlocutor (cf. Goffman, 1970), quien se vería obligado a decidir con qué forma prefiere ser tratado. La utilización de un tratamiento simétrico de tuteo está relacionada con la cortesía positiva, pues se interpreta, en general, como un modo de vinculación y confianza mutua entre los interlocutores, mientras que el uso de usted recíproco representaría la cortesía negativa, a través de la idea de "no invadir" o "amenazar" la imagen del otro individuo ${ }^{17}$.

\section{Variación en el uso de las formas de tratamiento}

El fenómeno de la variación pronominal se produce con relativa frecuencia en la muestra estudiada; en concreto, dentro del conjunto de entrevistas analizadas (dieciocho) se observan cambios en ocho de ellas, lo que representa $39 \%$ del total ${ }^{18}$. De entre estos casos, interesa distinguir aquellos en los que en una ocasión puntual se produce un cambio pronominal y, automáticamente el interlocutor retoma la forma apelativa que había esco-

17 Blas Arroyo (1994a: 21) relaciona la elección del pronombre usted con el "mantenimiento de estrategias más conservadoras y tradicionalmente más prestigiosas", vinculadas a la cortesía negativa, y destaca el aumento del tuteo en las comunidades hispánicas como un reflejo de la modernización y "democratización" de las sociedades contemporáneas "que ha contribuido a una valoración crecientemente positiva del tuteo como forma de tratamiento adecuada".

18 En este apartado solo se han tenido en cuenta los casos de variación en el uso de las formas de tratamiento sin mención explícita al respecto. Por tanto, no se han incluido como tal los ejemplos (1) a (4) ni en el cómputo, ni en el análisis. Algunas de estas entrevistas sí aparecerán recogidas de nuevo, porque a lo largo del encuentro se producirá algún cambio en el tratamiento no señalado de manera directa por los participantes. 
gido inicialmente, de aquellos en los que esto ocurre de manera continua. A continuación se presenta una gráfica que resume esta tendencia y, seguidamente, se incluye un estudio de corte cualitativo al respecto:

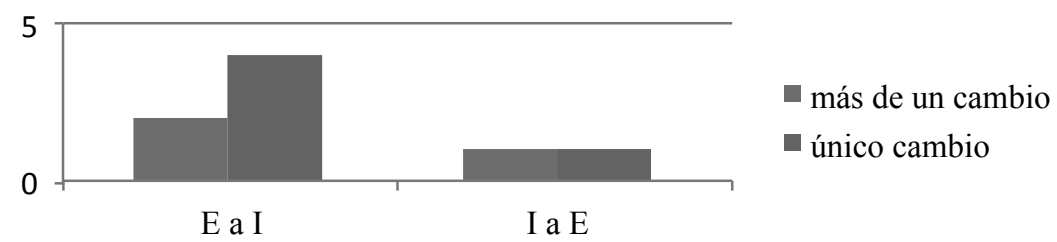

Gráfica 2: Variación tú/ Vd.

\subsection{Variación puntual}

Comenzando por los casos de variación puntual en las formas apelativas, interesa destacar que este hecho se produce en cinco entrevistas de la muestra analizada, lo que supone un $27,7 \%$ del total y, exceptuando un caso, en todos ellos tienen lugar del usted al tú y también en cuatro de ellos es la entrevistadora quien modifica la forma apelativa.

En lo relativo a los cambios de entrevistador a informante, tres de ellos se producen en sistemas de tratamiento asimétricos pertenecientes a las muestras SCOM_M23_005 (5), SCOM_H23_017 (6) y SCOM_H33_007 (7), respectivamente. Las tres entrevistadoras utilizan el pronombre usted y otros deícticos asociados a la misma forma, pero en un momento dado de la entrevista usan un pronombre posesivo, una desinencia verbal y un deíctico unido a una desinencia (respectivamente) asociadas al tuteo:

(5) E: ¿es tu nieta?

(6) $E$ : <ruido = "teléfono" $>$ coja no te preocupes

(7) E: y seguro que les tenías / en aquellos tiempos / miedo

En (5) el cambio se produce a los dieciséis minutos de comenzar la entrevista y coincide con un momento de distracción, en el que la nieta de la informante entra en la sala e interrumpe el desarrollo de la interacción, y da lugar a una pequeña conversación entre las tres. Es un uso espontáneo asociado a un contexto de los que Labov consideraba más pertinentes para obtener vernáculo: la entrada de terceras personas cercanas al entrevistado. La entrevistadora como hablante es sensible a la diferencia de contexto, lo que se refleja en su comportamiento lingüístico, aunque enseguida retoma el usted que había utilizado hasta el momento y que empleará hasta el final, aun viéndose interrumpida en otras dos ocasiones por la misma y por otras personas. En (6) el cambio también coincide con un momento de distracción debido a una llamada telefónica dirigida al informante que interrumpe la entrevista; tiene lugar a los veintinueve minutos de la grabación $\mathrm{y}$, tras producirse, la entrevistadora retoma la forma usted que había empleado hasta el momento. Por último, en (7) la modificación de la forma de tratamiento sucede a los treinta y seis minutos de la entrevista. Este cambio ocurre en una parte en la que el informante está narrando extensamente algunas experiencias desagradables que vivió con los médicos, los hospitales y su miedo hacia las inyecciones, y la entrevistadora participa en varias ocasiones; salvo en este caso en el 
que están abordando un tema que podría provocar cierto malestar o incomodidad, emplea siempre deícticos que corresponden al pronombre usted, a pesar de "olvidar" la invitación al tuteo (ejemplo 2).

Cabe señalar nuevamente que los interlocutores no se conocían hasta el momento de la entrevista y que el cambio se produce del usted que empleaban al tú. Las entrevistadoras comparten idénticos rasgos sociales: mujeres, estudiantes universitarias de $2^{\circ}$ o $3^{\circ}$ ciclo y menores de 25 años. Por su parte, los informantes son una mujer licenciada en Farmacia ya jubilada de 68 años (5), un varón funcionario licenciado en Derecho de 47 años (6) y un varón licenciado en Arquitectura de 62 años (7). Por tanto, parece que la variable edad, unida al nivel sociocultural de los entrevistados indujo a las tres entrevistadoras a decantarse por tratar de usted a sus respectivos interlocutores, si bien el cambio de planos discursivos o la temática de la entrevista motivaron la aparición espontánea de una forma de tuteo.

La última muestra de variación pronominal por parte del entrevistador se produce al comienzo de la entrevista SCOM_M23_004, que anticipamos en el apartado 4 (ejemplo 3): debido a un malentendido en el concierto de la cita, la entrevistadora está esperando más tiempo del previsto a que llegue la informante (mujer de 46 años). Cuando la recibe comienza tuteándola, tal vez por su aspecto joven ${ }^{19}$ o por el malestar producido por la dilatada espera (Placencia 2010: 367). No obstante, en el turno siguiente cambia al usted, que mantiene hasta que la entrevistada le pide que la trate de tú y a partir de ahí, la entrevista se desarrolla con un sistema de tuteo recíproco hasta el final:

(8) E: y estaba aquí esperándote

I: dije bueno <cita> entonces quedamos a las y media y cuando llegues a la parada me das $</$ cita $>$

E: $<$ simultáneo $>$ ¿a cuál? $</$ simultáneo $>$

I: $<$ simultáneo $>$ a la iglesia $</$ simultáneo $><$ cita $>$ me das un toque y te voy yo a buscar

$</$ cita $>$ y ahora dije $<$ cita $>$ pues andará perdida por ahi $</$ cita $>$

E: pues nada yo lo / del lo / del toque <simultáneo $>$ no me enteré para nada $</$ simultáneo $>$

I: $<$ simultáneo $>$ de eso no te enteraste claro $</$ simultáneo $>$

E: $<$ simultáneo $>$ yo $</$ simultáneo $>$

I: $\langle$ simultáneo $>$ bueno $</$ simultáneo $>$

E: pensé que habiamos quedado a las $<$ simultáneo $>$ tres y media $</$ simultáneo $>$

I: $<$ simultáneo $>$ claro $</$ simultáneo $>$

E: tampoco pasa nada / yo de hecho<alargamiento/> un ratillo si no venía la iba a $<$ simultáneo $>$ llamar </simultáneo $>[. .$.$] aunque no me acordé de pedirle el móvil$

En lo relativo a los informantes, solo hay un caso de variación puntual en la entrevista SCOM_M33_011, en la que inicialmente se establece un sistema de tratamiento asimétrico (ejemplo 4): la entrevista arranca sin advertir a la entrevistada (mujer de 75 años), quien tutea al entrevistador en el contacto inicial, en el que le pregunta por la finalidad del proyecto, se interesa por su ortodoncia dental y le pide que se cambie a otra habitación para "estar más cómodos".

(9) I: [...] tú ponte ahí / estamos mucho más cómodos yo creo / <ininteligible/> E: $<$ simultáneo $>$ no / me da igual $</$ simultáneo $>$

19 Al contrario de lo que sucede en el ejemplo (1) perteneciente a la entrevista SCOM_M23_018. 


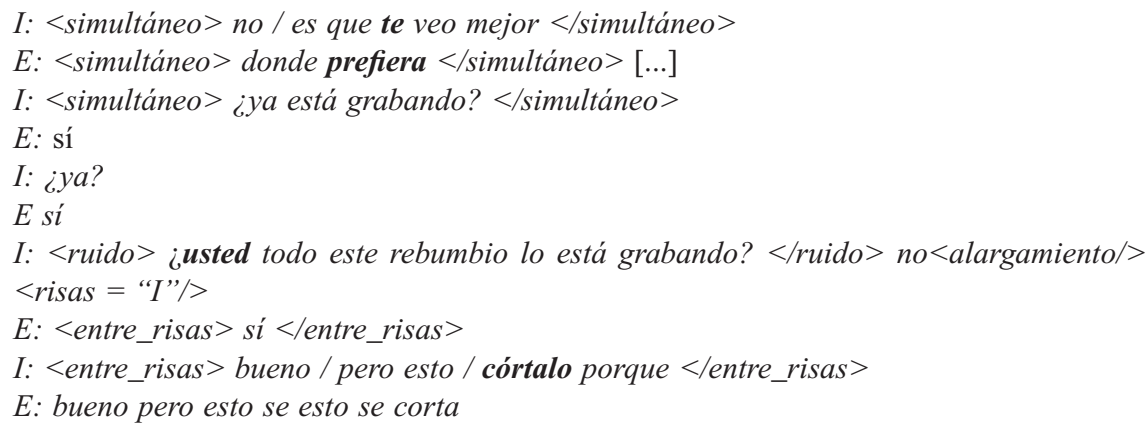

Cuando la entrevistada se percata de que la grabación ha comenzado sin previo aviso, le pregunta con la forma usted, la única que emplea en toda la entrevista, si efectivamente está grabando todo ese movimiento que no tiene que ver con la entrevista, tal y como ella la concibe. De este modo, parece querer distanciarse de su interlocutor de manera voluntaria, con objeto de hacerle notar que esa parte inicial que ha grabado no es apropiada, puesto que la entrevista propiamente no ha comenzado, está hablando de otros temas que considera no vinculantes para ese intercambio y ni siquiera han tomado asiento. Este uso de las formas de tratamiento con un fin distanciador aparece recogido por algunos autores (Rodríguez Mendoza, 2003; Kapovic, 2007), que indican que no acostumbra prolongarse en un extenso periodo de tiempo.

\subsection{Variación continua}

La variación constante en el uso de las formas de tratamiento es menos frecuente que la variación puntual y se produce en tres entrevistas del conjunto (16\%), en dos de ellas por parte del entrevistador y en una por el entrevistado.

Comenzando por la entrevista SCOM_H23_003, el entrevistador -varón de 20 añosopta por la forma usted para dirigirse a un interlocutor, también varón de 38 años, como señal de respeto y distancia. Sin embargo, a lo largo de la entrevista se producen cambios no consecutivos en la forma de tratamiento que utiliza. Así, hasta el minuto catorce, el entrevistador ustedea al informante y realiza preguntas y comentarios propios de una entrevista prototípica (10):

(10) a. E: [...] y llevar a cabo entrevista // bueno / pues $<$ alargamiento/> eeh / ¿a qué<alargamiento/> se dedica? / en la actualidad /

b. E: ¿o sea que trabaja de guía turístico?

c. E: eeh ¿ha perjudicado su<alargamiento/> / vamos / su trabajo / indirectamente con la ley antitabaco? /

Cuando el informante relata algunos aspectos anecdóticos de un viaje a Irlanda, como sus salidas nocturnas, el entrevistado muestra entonces una mayor cercanía con su interlocutor a través de risas, frases inconclusas y comentarios que buscan la complicidad de su oyente, y entonces cambia al tú, como una estrategia más de proximidad y de rebajar el nivel de formalidad del intercambio comunicativo: 
(11) a. E: <entre_risas> ¿qué te gusta más el ambiente de aquí o el de allá? </entre_risas> / b. E: y<alargamiento/> por ejemplo / cuando la gente se va a la calle / porque $s<$ palabra_cortada/ $>$ cierran locales $<$ fático $=$ "I" $/>/ \mathrm{mmm}$ yo no sé $/$ cuánto tiempo hace que / viniste para aqui pero $<$ alargamiento/ $>$ /

c. $E: i<$ sic $>$ conseguistes $</$ sic $>$ hacer amistades?

Sin embargo, al dejar el tema de Irlanda y otros secundarios derivados de este, el entrevistador retoma su rol y vuelve a la forma usted y a los enunciados de preguntas propios de una entrevista convencional:

(12) a. E: sí <risas = "E"/> de todas las fiestas que hay a lo largo del año <fático = "I"/> Semana Santa / Navidad / ¿con cuál se quedaría? / Carnavales

b. $E:<$ risas $=$ " $E$ "/> eeh cuando me dijo que estudió en la universidad <fático = "I"/> / le gustaba mucho leer /

c. E: <entre_risas> ¿que qué opina entonces del </entre_risas > de la programación de la televisión? /

Esta tendencia se repite sucesivamente a lo largo de todo el intercambio comunicativo y la alternancia de formas personales, en este caso, parece coincidir con la temática de la entrevista y otros aspectos vinculados a la formalidad del acto. La diferencia de edad entre interlocutores no es muy amplia y sus experiencias personales -estudios universitarios, estancias en el extranjero, salidas nocturnas, etc.- son similares, lo que también puede influir en que el entrevistador sienta una mayor proximidad con el entrevistado, y ello se manifieste en el cambio al tú. De acuerdo con Fontanella de Weinberg (1999), la forma tú se utiliza en situaciones de confianza, frente a usted, propio de situaciones de formalidad elevada, por lo que parece que en este caso el factor que determina la jerarquía es el nivel de formalidad de la situación comunicativa a tenor de la temática.

Otra muestra de variación continua en la elección de la forma de tratamiento, en este caso por parte del entrevistado, pertenece a la entrevista SCOM_H33_002: la entrevistadora -mujer de 19 años- selecciona de manera explícita el pronombre usted como forma en su primera intervención para dirigirse a su interlocutor, varón de 61 años:

(13) E: no sé / cuénteme <alargamiento/> // hábleme de usted // ¿es de aquí de toda la vida? <silencio/>

El entrevistado responde a la pregunta con una extensa narración sobre su infancia y llegada a la ciudad en la que no aparecen formas deícticas de segunda persona. Tras una interrupción externa, debida a una llamada al timbre, el informante le pide a la entrevistadora que detenga la grabación, y así utiliza por primera vez una forma desinencial asociada al usted:

(14) I: pare / pare si quiere <simultáneo/> / un mo <palabra_cortada/>

En cambio, tal vez desconcertado por la llamada, el entrevistado se dirige a la entrevistadora segundos después con el pronombre de segunda persona tú y seguidamente retoma la forma usted: 
(15) I: ¿tú venías con alguien? /

E: no < alargamiento/> /

I: es una llamada bastante extraña / es una voz una <alargamiento/> / mujer / dice que si podía hablar conmigo // <simultáneo $>$ sin más explicaciones $</$ simultáneo $>$

E: $<$ simultáneo $>$ no se preocupe o sea $</$ simultáneo $>$ si tiene que salir un $<$ simultáneo $>$ momento $</$ simultáneo $>$

I: <simultáneo > que no / </simultáneo > no / no / no / es que además ni sé de qué se $<$ simultáneo $>$ trata ¿no? $</$ simultáneo $>$

E: <simultáneo $>$ pues no / </simultáneo > para nada //

I: bueno / bueno pues le como le <transcripción_dudosa> iba diciendo </transcripción_dudosa $>/$ fue la única po <palabra_cortada $><$ ruido = "chasquido boca" $>>$ el el $<$ alargamiento/> o sea habia un cierto racismo

El informante trata de utilizar el pronombre usted como forma de tratamiento única, pero tutea a la entrevistadora en varias ocasiones. Así, en (16) al igual que ocurría en (5) y (6) el cambio de tratamiento coincide con diferentes planos discursivos: una interrupción externa y su contexto conversacional inmediato provoca un tú, y cuando el informante vuelve a situarse en el contexto de la entrevista regresa al usted, que utiliza además en una secuencia explícita de regreso (pues como le iba diciendo). Así, los diferentes planos discursivos marcan las distintas formas empleadas y, de acuerdo con los datos, el informante al situarse en su rol de "persona que está siendo entrevistada" utiliza la forma usted, mostrándose así solidario con su entrevistadora, que también lo emplea, y usa el tú en algunas partes de su discurso, por un cambio de plano discursivo o tal vez por la diferencia de edad que los separa, ya que generalmente los miembros mayores no suelen tratar de usted a los más jóvenes (Alba de Diego y Sánchez Lobato, 1980).

En los siguientes ejemplos (17) y (18) aparece otro caso de tuteo: el mismo entrevistado de (15) y (16) al abordar temas que pueden resultar controvertidos o incómodos para él, por tratar de su vida privada o de asuntos políticos que pueden generar confrontación utiliza el tuteo en ciertas ocasiones, como sucedía en (7) al introducir cuestiones como las enfermedades, hospitales, tratamientos médicos, etc. Así en (16) intenta justificar su situación personal y laboral presente; en definitiva, pretende aclarar que el hecho de estar jubilado no significa no desempeñar ningún tipo de actividad, como muchas veces se interpreta dicha situación:

(16) I: si // o <alargamiento/> me dedico<alargamiento/> pues ¿qué te diría yo? a jugar en la bolsa que no gano un duro <risas = "E"/> pero lo paso muy bien / <entre_risas $>$ o sea si </entre_risas > // si / realmente lo que he tratado es de no<alargamiento/> $<$ ruido = "chasquido boca" $>>$ o sea / a ver si me entiende / no ser un parado pasivo / en el sentido de decir <cita > bueno ¿y tú qué haces? </cita > / hombre si te refieres en<alargamiento/> el sentido de trabajos remunerados ninguno // pero procuras buscar cosas en las que<alargamiento/> estés ocupado //

En (17) el informante está hablando de asuntos políticos relacionados con las lenguas vernáculas de la península Ibérica e ideologías que considera extremas por parte de algunos partidos políticos que idolatran a Fidel Castro. Tras esta afirmación, trata de ilustrar con otro ejemplo de líder político que ninguno es ideal y, en medio de este controvertido discurso, de nuevo cambia la forma de tratamiento con la que se dirige a su interlocutora. 
(17) I: [...] te están hablando que sus ídolos pues son Fidel Castro no sé qué más < cita > <lengua $=$ "gallego" $>$ home </lengua $>$ no me fastidies oye / vamos a ser un poco congruentes $</$ cita> yo no te digo / que yo estoy de acuerdo que / que el Bush es un es es un carcamal o sea el Bush es una persona que no / pero bueno pero tampoco me vengas diciendo que Fidel Castro es un angelito hombre no vayamo <palabra_cortada/> vamos a irnos al<alargamiento/> sitio justo ¿no? / o sea por eso te digo que estamos hay veces en / hay cosas que $<$ alargamiento/> que que las ves y las oyes y las lees y tal <vacilación/> [...]

E: <simultáneo > aqui en Galicia es difícil / </simultáneo >

I: ¿entiende? y entonces pues eeh lo que pasa es que uno se calla ¿no?

En otra situación (18) comenta diversas actuaciones políticas y la entrevistadora se ríe, motivo por el que el informante le "reprocha" su actitud, de nuevo con una marca de tuteo. Este uso recuerda al de (9), en el que la entrevistada ustedea al entrevistador para preguntarle si está grabando la entrevista. En este caso, el cambio es del usted que utilizaba al tú, que parece emplear con el mismo fin:

(18) I: ¿y las otras qué pasa? o sea hay las de la <alargamiento $>$ vicepresidencia del gobierno y las otras que son de la Xunta son de segunda ¿no? / o sea <ruido = «chasquido boca»/>/ no sé / no te parece muy serio la cosa ¿no? I/

E: estuvieron en mi casa ayer hablando <entre_risas $>$ de eso </entre_risas $>/$

I: síl

E: por eso me río /

I: ya // sí / no / no sé es<alargamiento/> // yo hay cosas que no las ves o sea

Este mismo informante en algunas de sus narraciones se vale de consideraciones genéricas o impersonales, bien para apoyar sus afirmaciones o bien para no concretarlas, ya que no solo le atañen a él. Se trata de reflexiones genéricas en las que aparece un sujeto explícito (tú) o implícito con un valor no específico, cuyo referente es "uno", "la gente", "el mundo", etc. y no el destinatario presente en el acto comunicativo. En estos casos, la NGLE (2009: 16.2u) señala que

la interpretación genérica de la segunda persona se obtiene también en singular, sobre todo en contextos modales, irreales, y en general prospectivos. Se manifiesta este significado en la flexión verbal, como en Si quieres la paz, prepara la guerra (es decir, 'si uno quiere la paz...'); con los pronombres de segunda persona, sean átonos o tónicos y también con los posesivos.

Y, más adelante: “los posesivos tú y tus admiten un uso genérico o generalizados (a veces encubridor del hablante), en el que admiten la paráfrasis de 'uno cualquiera'. Comparten este rasgo con la flexión verbal de segunda persona y con los pronombres personales tú, te y $t i$ " (Ibid., 2009:18.2h).

Muestra de ello son los ejemplos (19) y (20) de la misma entrevista:

(19) I: $\mathrm{mmm} / /$ y<alargamiento/> o sea tenías además tenía que darte tu padre <fático = "E"> unos papel < palabra_cortada/> unas cartas autorizándote a viajar [...] y vas solo hasta allí o iba en avión por ejemplo ¿no? // y<alargamiento/> ento <palabra_cortada/ $>$ $y$ entonces a a te sorprende // sobre todo viviendo en aquella época $<$ fático $=$ " $E$ "/> // 
porque hoy en día la gente ya espabiló más pero en aquella época dices tú <cita > coño pues mira yo que me iba con catorce años hasta allá ¿eh? </cita> e iba // y bueno / y quieras que sí quieras que no pues te va<alargamiento/> condicionando ¿no? /

(20) I: teníamos en casa un<alargamiento/> comercio / de <alargamiento/ $>$ tejidos y de confección y todo eso $<$ silencio/ $>$ y $<$ alargamiento/ $>$ y ahi $/ /<$ ruido $=$ "chasquido boca" $/>$ porque en aquella época también te condicionaba mucho eso ¿no? [...] en el caso nuestro nos inclinaron más a a lo que era el comercio / por eso fue el hecho de mandarme a mí a Barcelona a estudiar Comercio / entonces <silencio/> bueno pues ya llega un momento en que<alargamiento/> mmm tú mismo te mentalizas en que $<$ alargamiento/> ese es $\boldsymbol{t} \boldsymbol{u}<$ alargamiento/ $>$ camino

Frente a estos casos de uso prototípico de formas no personales según la NGLE (2009), hay que mencionar otros en los que el informante pretende hacer una lectura genérica de una situación concreta y para ello emplea el pronombre usted e incluso utiliza ambas formas (usted y tú) dentro de una misma intervención:

(21) I: mire viajo mucho porque es que <alargamiento/> / <ruido = "chasquido boca"/> bueno viajo mucho / no / no viajo mucho / lo que ocurre es lo siguiente emmm // eh siempre<alargamiento/> basta que tengas una cosa para que te guste otra ¿no? o sea es que nosotros tenemos una casa en Ribeira // pero<alargamiento/> // en la playa ocurre una cosa que es que pasa como en el Antiguo Oeste // es decir / el el Oeste era tierras libres / tan pronto empezaron a poner alambradas y tal aquello se fastidió / bueno pues aqui pasa igual // usted en Ribeira tan pronto tenía una lancha y podía dejar la lancha donde te diera la gana no pasaba nada <silencio/> pero después empezaron a meterse y tal / y entonces ahora no $\boldsymbol{t}<$ palabra_cortada/> / tú una lancha tienes que tenerla con todos los papeles / no puedes apa < palabra_cortada/> dejarla en cualquier sitio / tienes que dejarla en un club náutico $<$ alargamiento/> o sea / te crea una serie de problemas ¿no?

(22) I: si si usted no tiene tradición o tiene costumbre a coger algo no <transcripción_dudosa $>$ pues </transcripción_dudosa> va usted a ir a<alargamiento/> / a repoblarlo ¿no? / entonces el único que puede repoblar es Medio Ambiente eso está clarísimo ¿no? / y si lo repuebla Medio Ambiente pues ya sabe que se va a cargar las especies autóctonas

(23) I: entonces usted claro si usted se imagina // eeh pues en Roma te sale pues un Quo Vadis o un<alargamiento/> / o el mismo Gladiador tal te salen unos palacios de los césares impresionantes ¿no?

Los ejemplos (21), (22) y (23) corresponden a fragmentos en los que se pone de manifiesto la variación existente en las formas de segunda persona, ya que parecen ser una muestra del intento del informante por ustedear a su interlocutora llevado al punto de variar la forma apelativa a la hora de generalizar. En estos casos, la interpretación particular no resulta coherente, porque el entrevistado desconoce si su interlocutora tenía una lancha en Ribeira (usted en Ribeira tenía una lancha) o si acostumbra ir de caza (si usted no tiene tradición). Solo podríamos aceptar esta interpretación para el ejemplo (23), ya que en este caso el informante no está presuponiendo cierta información, sino que está apuntando una hipótesis, correspondiente a la idea estereotipada que se tiene de la ciudad de Roma, hecho que se puede interpretar de manera genérica, pero también concreta. 
En todos estos casos la interpretación genérica del contenido parece la más adecuada, aunque la NGLE (2009 cf. 42) no menciona la posibilidad de usar la forma usted en este contexto. No obstante, autores como DeMello (2000) o León-Castro Gómez (2014), a partir de sendos análisis de corpus de la realidad hispánica sí ponen de manifiesto la utilización de esta forma genérica con el pronombre usted: "son muy escasos los ejemplos que hemos encontrado de hablantes que se dirijan a su interlocutor con la forma de tratamiento usted y empleen tú con un valor indefinido, donde el cambio de deíctico se debe a que el emisor se está refiriendo a sí mismo" (Ibid., 2014: 45). Otros autores también constatan este uso de la forma usted con valor generalizador que aparece cuando el hablante se dirige al interlocutor de usted, pero casi nunca cuando lo tutea (Fernández Ramírez, 1986). Por tanto, ante el desacuerdo bibliográfico, no queda claro si es la forma de ustedeo la que utiliza inadecuadamente y la de tuteo la que emplea de manera esperada en este contexto de impersonalización, de conformidad con la NGLE (2009) o, si por el contrario, la forma de tuteo es la inesperada en este caso, puesto que el interlocutor ustedea a la entrevistadora y, en consecuencia, la generalización tendría que hacerse bajo esa misma forma. En cualquier caso, la confluencia de ambas revela ciertas dudas en la elección pronominal.

En los casos registrados de variación entre las formas de tratamiento en esta entrevista, el informante comienza su intervención empleando el usted y posteriormente cambia al tú. La utilización en primer lugar de usted podría deberse a que es la forma con la que la entrevistadora lo trata, de modo que podría verse influido por ella, hasta que algún factor contextual o de otro tipo provoca un cambio en su tratamiento. Además, no hay que olvidar la naturaleza social de los interlocutores: el informante tiene 61 años y la entrevistadora 19, por lo que esa diferencia también es condicionante.

Finalmente, el último ejemplo de variación continua en el uso de las formas apelativas por parte del entrevistador es la entrevista SCOM_ M33_011, que vimos en (4), (8) y (9). El entrevistador ustedea a la informante, hasta que ella le permite tratarla de tú. Aunque inicialmente utiliza esa forma, acaba volviendo al usted seleccionado al comienzo y mezclando ambas formas, tal y como se puede ver en la formulación de distintas preguntas consecutivas:

(24) E: o sea que dio clases en primaria también

I: ¿qué? / en pri < palabra cortada/> sí en primaria en bachillerato

E: ah / pensaba que decía en / en el colegio

I: era secundaria / era secundaria [...]

E: ¿alguna vez te pasó algo así con un niño?

I: ¿qué? con niños no / con alumnos nunca me pasó nada ¿¿eh? / nunca [...]

E: <silencio> ¿y ya decidió irse?

I: ya / y no tenías nómina o sea te daba el dinero / y no tenías no figurabas en una nómina [...]

E: ¿y cómo recuerdas ese viaje?

I: mmm ese viaje muy bien fue un viaje muy bonito

La variación incluso se produce entre enunciados muy próximos, casi inmediatos:

(25) E: $<$ simultáneo $>$ ahora / que hablabas un poco de $<$ alargamiento/ $>$ de $</$ simultáneo $>$ I: $<$ simultáneo $>$ y de <palabra_cortada/ $>/ y$ después / y después de / </simultáneo $>$ de eso / mmm ya si quieres dejamos eso / si quieres te hablo ya un poco de <vacilación/> cuando ya paso a profesora si no te hablamos de otra cosa 
E: $<$ simultáneo $>$ de $<$ alargamiento/ $></$ simultáneo $>$

I: $<$ simultáneo $>$ de cla $<$ palabra_cortada $></$ simultáneo $>$ de la ciudad o de algo

E: hable de $<$ alargamiento/ $><$ simultáneo $>$ su vida familiar $</$ simultáneo $>$

I: $<$ simultáneo $>$;la ciudad? $</$ simultáneo $>$

E: $<$ simultáneo $>$ si $<$ alargamiento/ $>$ bueno $</$ simultáneo $>$

I: $<$ simultáneo $>$ ¿de la vida familiar mía? </simultáneo $>$

E: si le parece

I: $<$ simultáneo $>$ pues mira mi vi $<$ palabra_cortada $></$ simultáneo $>$

E: <simultáneo $>$ ¿cuándo conociste a tu marido? $</$ simultáneo $>$

I: pues mira mi vida familiar / mmm te voy a contar / vivíamos primero ahí /

A diferencia de los restantes casos estudiados en este trabajo, no se encuentran recurrencias en el análisis lingüístico que evidencien una distribución situacional de cada pronombre para determinar en qué contextos se utiliza una u otra forma apelativa. La razón de esta alternancia se puede justificar a partir de las diferencias sociales existentes entre interlocutores, tanto de edad como de categoría académica (becario frente a catedrática) que dificultan al entrevistado tutear a la informante, aunque ella le haya dicho que puede hacerlo al tratarse de una situación de una jerarquía social muy marcada. En este sentido, Hickey y Vázquez Horta (1990: 74) y Matte Bon (1995: 244) justifican el uso de usted en relaciones jerarquizadas y, sobre todo, al dirigirse a personas desconocidas o mayores con las que no se mantienen relaciones de confianza.

\section{Conclusiones}

El uso de las formas de tratamiento es un asunto de difícil interpretación. No existe unanimidad en cuanto al enfoque teórico más adecuado para su estudio ni en relación con los factores que señala la bibliografía especializada como determinantes en la elección de una u otra forma de tratamiento. El trabajo más aceptado es el de Brown y Gilman (1968), si bien, como se ha visto, no resuelve por completo la complejidad de la situación.

En este artículo se ha llevado a cabo un análisis cualitativo sobre la distribución de uso de las formas de tratamiento en el corpus de entrevistas semidirigidas de Santiago de Compostela. Para completarlo, se han aducido otros trabajos y otras teorías que mencionan diferentes factores que provocan un desequilibrio en la relación social entre hablantes. Dichos factores suelen dividirse entre los que tienen que ver con la naturaleza social de los individuos (edad, sexo, nivel sociocultural, etc.) y la relación que mantienen en una determinada situación (jerarquía, proximidad...). En este sentido, en diversas investigaciones, incluida esta, se constata que es la edad la variable que marca una mayor distancia social y, por ello, es la que más influye en los hablantes para seleccionar una forma apelativa u otra. Otros posibles parámetros como el nivel sociocultural, en este caso, a priori, son compartidos por los dos interlocutores y, en cuanto al sexo, no se han hallado evidencias en el análisis acerca de su posible influencia.

La alusión explícita al tratamiento y a un posible cambio no es muy habitual y, en la muestra estudiada, aparece fundamentalmente como una invitación al tuteo. Frente a estos casos, interesa señalar el elevado número de entrevistas en las que se registra algún tipo de variación en el uso de las formas de tratamiento. En conjunto, como se ha podido observar, los cambios se producen por distintas razones, que se resumen a continuación: 
1. De manera explícita, para introducir un sistema de tratamientos simétrico y establecer una situación solidaria. Ejemplos (2), (3) y (4).

2. Ante un cambio de planos discursivos por interrupciones externas. Ejemplos (5), (6) y (15).

3. Para manifestar un cierto reproche o marcar un distanciamiento voluntario. Ejemplos (9) y (18)

4. Para mantener la formalidad de la situación y situar el rol de entrevistador-ejemplos (10), (11) y (12)- y de entrevistado -ejemplo (14)-. En este último caso, además, para mostrarse solidario con el interlocutor utilizando la misma forma de tratamiento con la que está siendo tratado.

5. En el contacto inicial, debido a que el interlocutor tiene una edad que no se corresponde con la esperada (ejemplo 1, de forma directa) o porque ha causado algún malestar en el emisor. Ejemplo (8)

6. Por el tratamiento de temas incómodos. Ejemplos (7), (18) y (19).

7. Ante razones de diferencia social. Ejemplos (24) y (25).

8. En contextos impersonales o genéricos. Ejemplos (21), (22) y (23).

La variación de formas apelativas aparece en aquellos contextos en los que, al menos, uno de los interlocutores utiliza el pronombre usted como forma de tratamiento, lo que parece indicar que en las situaciones de relación solidaria es menos probable que se produzcan alternancias. Este fenómeno revela una falta de pericia en el uso de usted, ya que con una relativa facilidad los interlocutores pueden verse influidos por factores contextuales o externos para modificar el tratamiento que están utilizando, de manera que se puede confirmar que la forma no marcada en el español peninsular es tú (Hickey y Vázquez Horta, 1990: 75).

En suma, se ha comprobado que el uso de las formas de tratamiento no es algo estable y sujeto a reglas. Los hablantes seleccionan uno u otro pronombre dependiendo de dónde consideren que deben situarse respecto a su interlocutor, en función de diversos factores que, según los datos recogidos tienen que ver con la edad de los interlocutores y, en algunos casos también con la formalidad de la situación comunicativa.

\section{Referencias bibliográficas}

\section{Fuentes:}

ESLORA: Corpus para el estudio del español oral: http://galvan.usc.es/eslora (17-04-15).

PRESEEA: Proyecto para el estudio sociolingüistico del español de España y de América: http://preseea.linguas.net/ (17-04-15).

Aguado Candanedo, D. (1981): “Análisis sociolingüístico del uso de tú/ usted en los estudiantes universitarios de Bilbao", Letras de Deusto, 21, págs. 165-184.

Aijón Oliva, M. Á. (2009): “Tú y usted como estrategias de estilo y persuasión en la comunicación publicitaria”, Tonos, Revista electrónica de estudios filológicos, 18: http://www. um.es/tonosdigital/znum18/secciones/estudio-1-tu_y_usted.htm (12-11-14).

Alba de Diego, V. y J. Sánchez Lobato (1980): “Tratamiento y juventud en la lengua hablada. Aspectos sociolingüísticos", Boletín de la Real Academia Española, 21, págs. 165-184.

Albelda Marco, M. (2005): "Cortesía en diferentes situaciones comunicativas. La conversación coloquial y la entrevista sociológica semiformal”. En Bravo D. y A. Briz (coords.), págs. 109-134. 
Blas Arroyo, J. L. (1994a): "Los pronombres de tratamiento y la cortesía”, Revista de Filología de la Universidad de La Laguna, 10, págs. 7-36.

Blas Arroyo, J. L. (1994b): “Tú y Usted: dos pronombres de cortesía en el español peninsular actual. Datos de una comunidad peninsular", Estudios de Lingüística de la Universidad de Alicante (ELUA), 10, págs. 21-44.

Blas Arroyo, J. L. (1995): “Un ejercicio de sociolingüística interaccional: el caso de los pronombres de tratamiento en el español actual", Verba, 22, págs. 229-252.

Borrego, J.; J. J. Gómez Asencio y J. A. Pérez Bowie (1978): “Sobre el tú y el usted”, Studia Philologia Salamanticensia, 2, págs. 53-67.

Bravo, D. y A. Briz (coords.) (2005): Pragmática sociocultural. Estudios sobre el discurso de cortesía en español. Barcelona, Ariel.

Bravo, D. (2005): “Categorías, tipologías y aplicaciones. Hacia una redefinición de la cortesía comunicativa", en Bravo, D. y A. Briz (coords.), págs. 21-52.

Brown R. y A. Gilman (1968): "The pronouns of power and solidarity”, Semantic Aspects of style, págs. 253-276.

Brown, P. y S. Levinson ([1978] 1987): "Universals in Language Usage: Politeness Phenomena”. En Godoy, E. (ed.). Questions on Politeness. Cambridge, Cambridge University Press, págs. 56-289.

Calderón Campos, M. (2010): “Formas de Tratamiento". En Aleza Izquierdo, M. y J. M. Enguita Utrilla (coords.): La lengua española en América: normas y usos actuales, Valencia, Universidad de Valencia, págs. 225-236.

Calderón Campos M. y F. Medina Morales (2010): “La historia y situación actual de los pronombres de tratamiento en el español peninsular". En Hummel, M., B. Kluge y M. E. Vásquez Laslop (eds.), págs. 195-222.

Calsamiglia, H. y A. Tusón (2007 [1999]): Las cosas del decir. Barcelona, Ariel.

Carrasco Santana, A. (1999): "Revisión y evaluación del modelo de cortesía de Brown y Levinson”, Pragmalingüistica, 7, págs. 1-44.

Cestero Mancera, A. M. (2013): "El proyecto para el estudio sociolingüístico del español de España y América (PRESEEA)”, Español Actual, 98, págs. 227-234.

Cots, J. M. (1998): Teaching by chatting, a pragmatic analysis of instructor-student conversations at an American University. Lleida, Universitat de Lleida.

Davies, M. (2002): Un corpus anotado de 100.000.000 palabras del español histórico y moderno: www.corpusdelespanol.org (06-04-15).

DeMello, G. (2000): “Tú" impersonal en el habla culta", Nueva Revista de Filología Hispánica, 48: http://redalyc.org/articulo.oa?id=60248205 (06-04-15).

Escandell Vidal, V. (1995): "Cortesía, fórmulas convencionales y estrategias indirectas", Revista española de lingüística, 25/1, págs. 31-66.

Escandell Vidal, V. (2006): Introducción a la pragmática. Barcelona, Ariel.

Escavy Zamora, R. (2008): Pragmática y subjetividad lingüística. Murcia, Universidad de Murcia, Servicio de publicaciones.

Fernández, M. (2003): “Constitución del orden social y desasosiego: pronombres de segunda persona y formulas de tratamiento en español". Ponencia plenaria en el coloquio Pronoms de $2^{\circ}$ personne et formes d'adresse dans les langues d'Europe: http://cvc.cervantes. es/obref/coloquio_paris/indice.htm (06-04-15). 
Fernández, M. (2006): "Pronombres de segunda persona y fórmulas de tratamiento en español: una bibliografía", Linred: lingüistica en la red, 4: http://www.linred.es/informacion_pdf/informacion13_06072006.pdf (06-04-15).

Fernández Ramírez, S. (1986): Gramática española IV. El verbo y la oración. Madrid, Arco Libros.

Fernández Sanmartín, A.; M. García Salido, M. Recalde y V. Vázquez Rozas (2008): “Reflexiones metodológicas sobre la técnica de la entrevista semidirigida", Actas del XV Congreso Internacional de la ALFAL: http://alfal.easyplanners.info/programa/buscar. php?id_tl=886\# (06-04-15).

Fontanella de Weinberg, B. (1999): "Sistemas pronominales de tratamiento usados en el mundo hispánico". En Bosque, I. y V. Demonte (dirs.): Gramática descriptiva de la lengua española. Madrid, Espasa Calpe, págs. 1401-1425.

Frías Conde, X. (2011): “Los pronombres de cortesía. Entre la lingüística, la pragmática y la traductología", Seminario Ciencia del lenguaje y lingüística hispánica: http://uned. academia.edu/XavierFrias/Teaching/28902/Los_pronombres_de_cortesia (06-04-15).

Garrido Medina, J. C. (1992): "Semántica histórica del español: problemas y propuestas (a propósito de la evolución actual de las formas de tratamiento)". En Ariza Viguera, M. (coord.): Actas del II Congreso Internacional de Historia de la Lengua Española. Sevilla, Pabellón de España Editores, págs. 1055-166.

Goffman, E. (1970 [1967]): Ritual de la interacción. Buenos Aires, Tiempo Contemporáneo. Havertake, H. (1994): La cortesía verbal. Estudio pragma-lingüístico. Madrid, Gredos.

Hernández Flores, N. (2005): "La cortesía como búsqueda del equilibrio de la imagen social”. En Bravo, D. y A. Briz (coords.), págs. 95- 108.

Hickey, L. e I. Vázquez Orta (1990). "El empleo de tú y usted en el discurso publipropagandístico", Revista Española de Lingüística Aplicada, 6, págs. 73-82.

Hummel, M.; B. Kluge y M. E. Vásquez Laslop (eds.) (2010): Formas y fórmulas de tratamiento en el mundo hispánico. México D.F/ Graz, Universidad Karl Franzens de Graz /El Colegio de México.

Kapovic, M. (2007): "Fórmulas de tratamiento en dialectos de español; fenómenos de voseo y ustedeo", Hyeronimus, 1, págs. 65-87.

Labov, W. (1966): Principios del cambio lingüístico. Madrid, Gredos.

León-Castro Gómez, M. (2014): "Sobre el empleo de la segunda persona del singular como mecanismo de indefinición referencial en el habla culta. Diferencias entre las formas túl vos y usted", Lingüística y literatura, 65, págs. 37-63.

Llisterri, J. (1999): “Transcripción, etiquetado y codificación de corpus orales". En Gómez Guinovart, J.; A. M. Lorenzo Suárez, J. Pérez Guerra y A. Álvarez Lugrís (coords.): Panorama de la investigación en lingüística informática, Revista Española de Lingüistica Aplicada (volumen monográfico), págs. 53-82.

Mas Álvarez, I. (2014): "Formas de tratamiento y enseñanza del español como lengua extranjera", RedELE, 26: http://www.mecd.gob.es/dctm/redele/Material-RedEle/ Revista/2014_26/2014_redELE_26_06Inmaculada\%20Mas\%20\%C3\%81lvarez. pdf?document $\overline{\mathrm{Id}}=0901 \mathrm{e} \overline{\overline{2}} \mathrm{~b} 81946 \mathrm{da} 7$ (07-04-15).

Matte Bon, F. (1995): Gramática comunicativa del español. De la lengua a la idea. Madrid, Edelsa. 
Medina López, J. (1990): "Sobre los conceptos de «poder» y «solidaridad» en las formas de tratamiento". En Álvarez Martínez, Ma Á. (ed.): Actas del congreso de la Sociedad Española de Lingüística: XX aniversario, 2, Madrid, Gredos, págs. 630-638.

Molina Martos, I. (2002): "Evolución de las fórmulas de tratamiento en la juventud". En Rodríguez González, F. (coord.): El lenguaje de los jóvenes, Madrid, Ariel, págs. 97-121.

Moreno Fernández, F. (1996): "Metodología del 'Proyecto para el estudio sociolingüístico del Español de España y de América' (PRESEEA)”, Lingüística, 8, págs. 257-287.

Moreno Fernández, F. (2005): “Corpus para el estudio del español en su variación geográfica y social. El corpus PRESEEA”, Oralia, 8, págs. 123-139.

Montero Curiel, P. (2011): “Aproximación sociolingüística a las fórmulas pronominales de tratamiento en el habla juvenil”, Revista de estudios de juventud, 93, págs. 105-116.

Morín Rodríguez, A. (1997): "Independencia de variables en la investigación sociolingüística a través del análisis del tratamiento". En Almeida, M. y J. Dorta (coords.): Contribuciones al estudio de la lingüística hispánica. Homenaje al profesor Ramón Trujillo. Barcelona, Montesinos Editor, págs. 287-294.

Paredes, F. (2010): “¿Es factible un cuestionario estándar para el estudio del tratamiento? La experiencia del proyecto PRESEEA en Madrid y Alcalá de Henares". En Hummel, M.; B. Kluge y M. E. Vázquez Laslop (eds.), págs. 163-191.

Pedroviejo Esteruelas, J. M. (2003): "Formas de tratamiento pronominales y nominales en el siglo XX. Análisis de dos obras de teatro: Historia de una escalera y Bajarse al moro", Interlingüística, 14, págs. 388-397.

Pedroviejo Esteruelas, J. M. (2006): "Un estudio sociolingüístico. Sistemas de tratamiento de la Universidad de Valladolid", Tonos. Revista electrónica de estudios filológicos, 11: http://www.um.es/tonosdigital/znum11/estudios/20-tratamiento.htm (07-04-15).

PRESEEA (2003): Metodología del Proyecto para el estudio sociolingüístico del español de España y de América PRESEEA: http://preseea.linguas.net (17-04-15).

PRESEEA (2008): Marcas y etiquetas mínimas obligatorias, Versión 1.0.: http://preseea. linguas.net (17-04-15).

Real Academia Española y Asociación de Academias de la lengua española (2009): Nueva gramática de la lengua española. Madrid, Espasa.

Real Academia Española: Banco de datos (CREA) (en línea). Corpus de referencia del español actual: http://www.rae.es (07-04-15).

Recalde, M. y V. Vázquez Rozas (2009): "Problemas metodológicos en la formación de corpus orales”. En Cantos Gómez, P. y A. Sánchez Pérez (eds.): A Survey on Corpusbased Research / Panorama de investigaciones basadas en corpus. Murcia, AELINCO (Asociación Española de Lingüística de Corpus), págs. 37-49.

Ridruejo Alonso, E. (1989): Las estructuras gramaticales desde el punto de vista histórico. Madrid, Síntesis.

Rodríguez Mendoza, J. (2003): Lenguaje y sociedad. La alternativa tú/usted en San Sebastián de la Gomera. Tesis doctoral, Universidad de la Laguna: ftp://tesis.bbtk.ull.es/ ccssyhum/cs150.pdf. (06-04-15).

Sanromán, B. (2013): "Las formas de tratamiento del español peninsular actual. Los estudiantes de poblaciones gallegas", Représentations des formes d'adresse dans les langues romanes, 89: http://rudar.ruc.dk/handle/1800/8460. (07-04-15). 
Silva-Corvalán, C. (2001): Sociolingüistica y pragmática del español. Washington, Georgetown University Press.

Solé, Y. (1978): "Sociocultural determinants of symmetrical and asymmetrical address forms in Spanish”, Hispania, 61, págs. 940-949.

Vázquez Veiga, N. (1995): "Corpus de lengua hablada en la ciudad de A Coruña: El rol de entrevistador en la conversación semidirigida", Moenia, 1, págs. 181-202.

Vázquez Rozas, V. (en prensa): "ESLORA: Diseño, codificación y explotación de un corpus oral de español de Galicia": http://gramatica.usc.es/ vvazq/pdf_publ/corpus_eslora_pres.pdf (13-04-15).

Weinerman, C. (1976): Sociolingüística de la forma pronominal. México, Trillas.

Zambrano-Paff, M. (2006): “That Woman se convierte en Esa señora. El uso de marcadores de cortesía para proyectar una imagen más formal y salvaguardar la imagen de los interlocutores en los tribunales de inmigración”, III Coloquio Internacional Edice. Valencia, Sgel. 